NBSIR 83-2705

\title{
Development of Power System Measurements -- Quarterly Report July 1,1982 to September 30, 1982
}

U.S. DEPARTMENT OF COMMERCE

National Bureau of Standards

Center for Electronics and Electrical Engineering

Electrosystems Division

Washington, DC 20234

May 1983

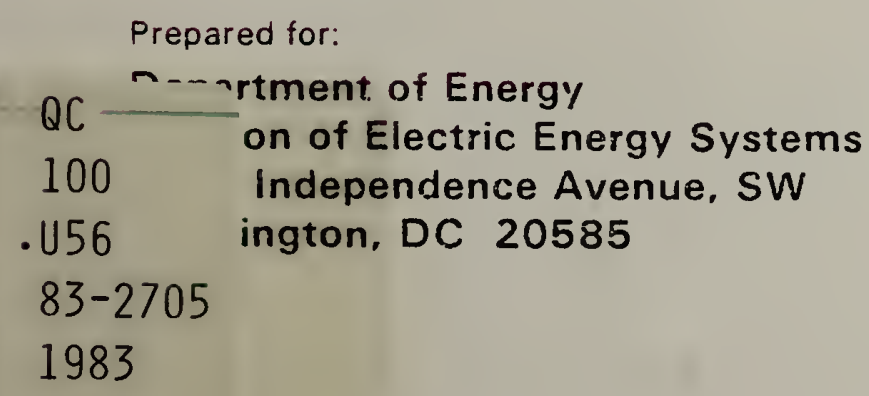





\section{DEVELOPMENT OF POWER SYSTEM}

MEASUREMENTS -- QUARTERLY REPORT

JULY 1, 1982 TO

SEPTEMBER 30, 1982

R. E. Hebner, Editor

U.S. DEPARTMENT OF COMMERCE

National Bureau of Standards

Center for Electronics and Electrical Engineering

Electrosystems Division

Washington, DC 20234

May 1983

Prepared for:

Department of Energy

Division of Electric Energy Systems

1000 Independence Avenue, SW

Washington, DC 20585

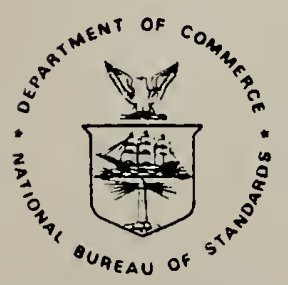

U.S. DEPARTMENT OF COMMERCE, Malcolm Baldrige, Secretary NATIONAL BUREAU OF STANDARDS, Ernest Ambler, Director 

Foreword

This report summarizes the progress on four technical investigations during the fourth quarter of FY 1982. Although reasonable efforts have been made to ensure the reliability of the data presented, it must be emphasized that this is an interim report so that further experimentation and analysis may be performed before the conclusions from any of these investigations are formally published. It is therefore possible that some of the observations presented in this report will be modified, expanded, or clarified by our subsequent research. 


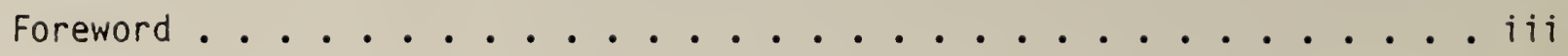

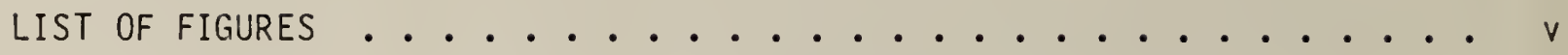

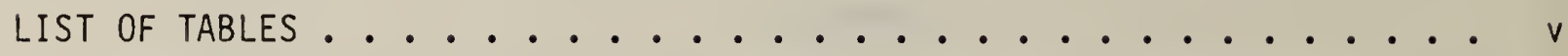

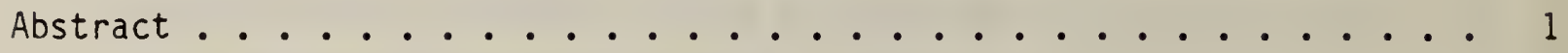

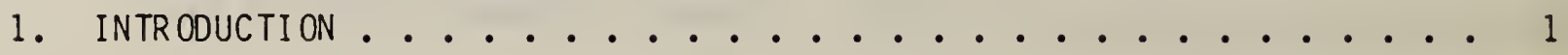

2. DC FIELDS AND ION MEASUREMENTS

Subtask No. A018 .................. 1

3. TECHNICAL ASSISTANCE FOR FUTURE INSULATION SYSTEMS RESEARCH

Subtask No. A053 ................ 5

4. OPTICAL MEASUREMENTS FOR INTERFACIAL CONDUCTION AND BREAKDOWN

IN INSULATING SYSTEMS

Subtask No. A057 . . . . . . . . . . . 13

5. ACTIVE INSULATORS FOR INSULATION AND SURGE SUPPRESSION

Subtask No. A057 ...................... 14

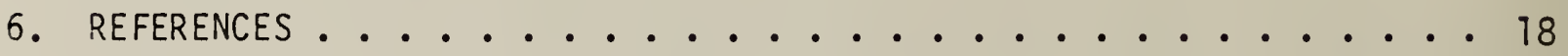


Figure 1. Schematic view of parallel plate apparatus and rotor-stator

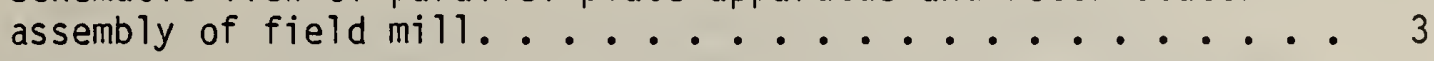

Figure 2. Measured discharge pulse rate versus applied voltage for positive, point-plane corona in $\mathrm{SF}_{6}$ at a pressure of $300 \mathrm{kPa}(\sim 3 \mathrm{~atm})$ for the different indicated conditions of gap irradiation. .............. 8

Figure 3. Relative difference in electron avalanche counts for light beam on $\left(\mathrm{N}_{1}\right)$ and light beam off $\left(\mathrm{N}_{2}\right)$ measured for two different indicated conditions of gap irradiation for a positive point electrode in $\mathrm{O}_{2}$ at a pressure of $200 \mathrm{kPa}(\sim 2 \mathrm{~atm})$. The error bars indicate the statistical uncertainties in the measurements................ 11

Figure 4. Equivalent circuit for single phase transmission line with an

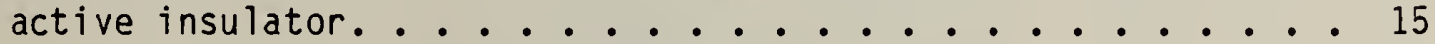

Figure 5. Equivalent circuit for a voltage source with breaker resistance

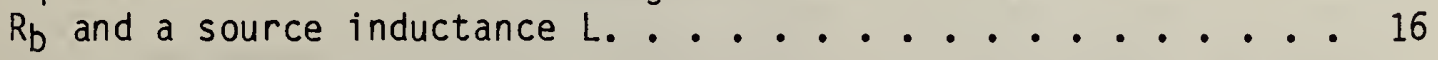

\section{LIST OF TABLES}

Page

Table 1. Error sources for parallel plate apparatus ........ 4 



\title{
DEVELOPMENT OF POWER SYSTEM MEASUREMENTS -- QUARTERLY REPORT JuTy 1, 1982 to September 30, 1982
}

\author{
R. E. Hebner, Editor
}

\begin{abstract}
This report documents the progress on four technical investigations sponsored by the Department of Energy. Three were performed by the Electrosystems Division, the National Bureau of Standards and the fourth by the Department of Electrical Engineering of the University of Southern California. The work described covers the period from July 1, 1982 to September 30, 1982. The report emphasizes the calibration of instruments designed to measure the $60-\mathrm{Hz}$ electric field in biological exposure facilities, the determination of the role of photodetachment of $\mathrm{SF}_{6}$ corona discharges, the measurement of failure mechanisms in liquid/solid insulating systems, and the development and behavior of active insulators.
\end{abstract}

Key words: cables; composite insulation; dc fields; high voltage; incipient fault; insulation; liquid breakdown; $\mathrm{SF}_{6}$; space charge; transformer oil.

\section{INTRODUCTION}

Under an interagency agreement between the U. S. Department of Energy and the National Bureau of Standards, the Electrosystems Division, NBS, has been providing technical support for DOE's research on electric energy systems. This support is concentrated in three areas -- the measurement of electric fields, the measurement of partial discharge phenomena in gaseous dielectrics, and the measurement of interfacial electrostatic field distributions and of space charge density. The technical progress made during the quarter July 1, 1982 to September 30, 1982 is summarized in this report.

\section{DC FIELDS AND ION MEASUREMENTS Subtask No. A018}

The objectives of this investigation are to develop methods to evaluate and calibrate instruments which are used, or are being developed, to measure the electric field, conductivity, the space-charge density, and current density in the vicinity of high-voltage dc transmission lines and in apparatus designed to simulate the transmission line environment; to provide electrical measurement support of DOE-funded efforts to determine the effects of ac fields on biological systems and to provide similar support for biological studies which are funded by the State of New York.

To support ac measurements, a magnetic field probe has been obtained and its evaluation was initiated. The evaluation of dc instrumentation has focused on the off-ground operation of ion counters and on electric field meters. In applications near high voltage dc lines, it is very convenient to operate an ion counter in such a manner that the instrument protrudes above the ground plane. In this configuration, the investigator has the option of grounding the counter, insulating the counter and 
allowing it to assume the potential determined by the experimental conditions, or biasing the counter to a preselected value. To determine the effect of counter potential on counter response, a model dc transmission line was constructed as was a fiber optic system to couple the counter output to grounded recording equipment. Preliminary results have been obtained and this investigation is continuing.

A new electric field meter was received and tested during this reporting period. In spite of some damage sustained during shipment, the field meter functioned well enough to be evaluated using the NBS parallel plate apparatus. A field-mill-type field probe was sought because earlier studies at NBS [1] demonstrated that this type of probe, when operated in the presence of large ion current densities, will have smaller measurement errors than a vibrating-plate-type probe. The evaluation of the recently arrived device demonstrates, however, that field mills can malfunction in the presence of large space-charge currents, if not properly designed.

The experimental setup for the tests is shown schematically in the inset of figure 1. Details on the operation of the parallel plate apparatus are given elsewhere [1] and are not necessary for the discussion presented here. Also shown in figure 1 is a sketch of a portion of the field mill sensing head which is mounted in a cylindrical metal housing. The grounded rotor periodically interrupts the electric field lines impinging on the sensing electrode, or stator, producing a time-varying induced current to ground. The signal voltage across resistor $R$ is then amplified and the signal is applied to a phase sensitive detector. The output signal from the phase sensitive detector, monitored with a digital voltmeter, was found to be a linear function of the electric field strength between the parallel plates in the absence of space charge.

Measurements of electric fields containing positive space charge were also made with the newly acquired field mill and compared with simultaneous measurements obtained with a second field mill. The performance of the second field mill has previously been characterized and is referred to as the "NBS field mill" in table 1. While less portable and having signal stability problems, it is able to measure electric fields without significant errors due to the presence of space charge currents [1]. The ratios of the field strength with and without positive space charge at fixed voltages applied to the parallel plates were recorded and are presented in table $1(a)$. When the ion current density $J$ becomes limited by space charge, as was the case during the present tests, the electric field is enhanced in our apparatus by a little more than $50 \%$. The results in table 1 (a) show that the recently acquired field mill indicates field values that are too low. When the electric field was turned off, a change in the zero-field reading was also observed for the new field meter. This negative offset decayed over many minutes until the original zero-field signal was restored. Correlated with this decay was the reduction in. amplitude of a small, approximately sinusoidal, signal from the stator. The stator signal waveform was observed via a buffered output following the first stage of amplification. This correlation suggested that the offset was not due to a deficiency in the electronics which analyze the "output signal," as shown in figure 1. It was more likely due to the properties of the basic field mill assembly itself. 


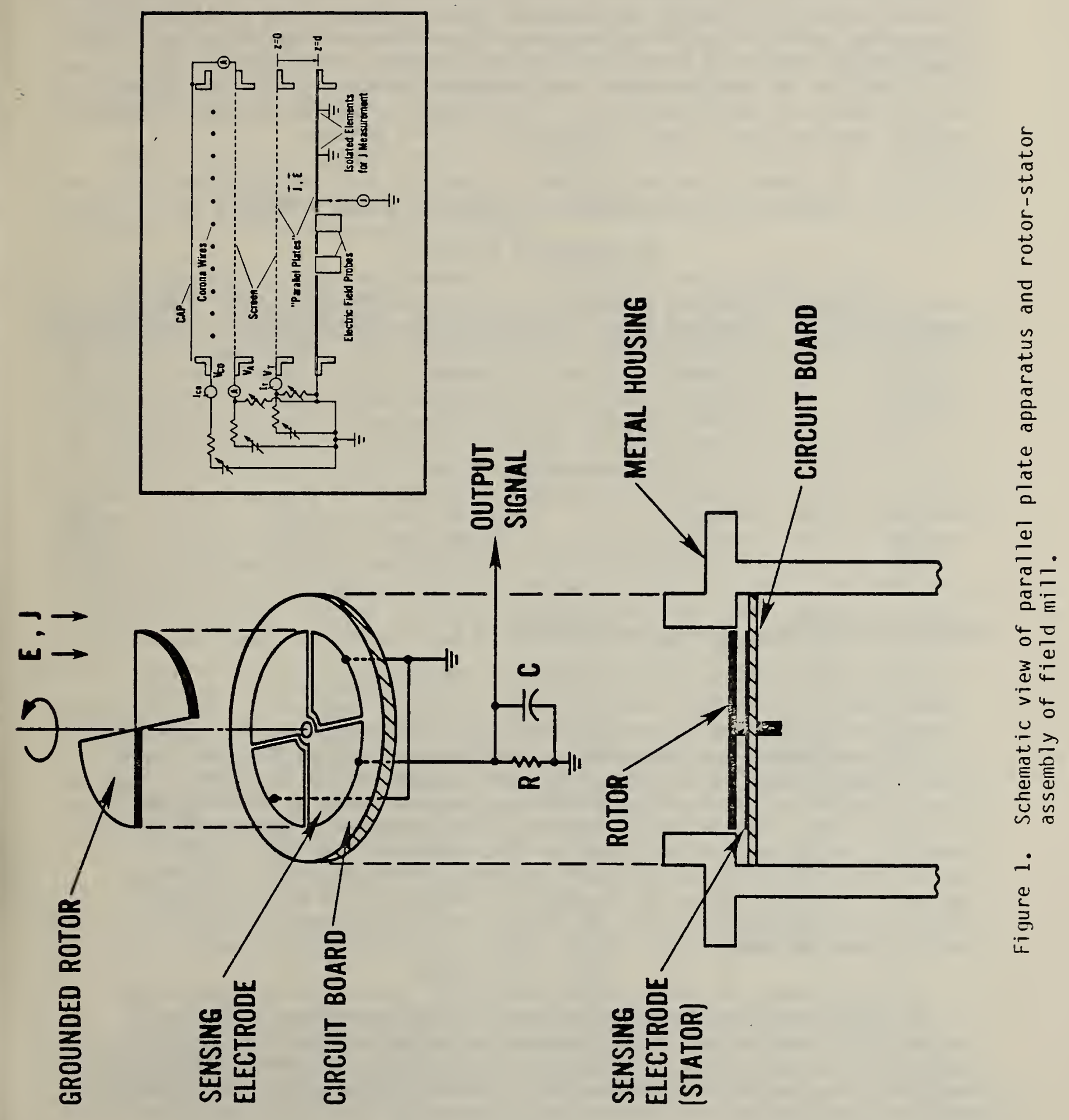


The long decay constant suggested that the exposed circuit board on which the stator was mounted (fig. 1) was charging up when the system contained space charge. To test this hypothesis, the circuit board was covered with grounded aluminum foil and the field measurements were repeated. The disagreement between the two field mill readings as well as the charging effect were both eliminated. Table 1 (b) shows the results of several measurements. The third entry is for the case when the chopping frequency on the new field mill is reduced from 100 to $86 \mathrm{~Hz}$. The scatter in the NBS field mill data reflects the previously noted instability of this device.

\section{Table 1. Error sources for parallel plate apparatus}

(a) Uncovered insulator

\begin{tabular}{|c|c|c|c|c|}
\hline $\begin{array}{l}\text { Parallel plate } \\
\text { spacing (m) } \\
\end{array}$ & $\begin{array}{l}\text { Parallel plate } \\
\text { voltage }(\mathrm{kV}) \\
\end{array}$ & $\begin{array}{c}J \\
\left(\times 10^{-6} \mathrm{~A} / \mathrm{m}^{2}\right) \\
\end{array}$ & $\begin{array}{l}\text { New field mill } \\
E(J \neq 0) / E(J=0)\end{array}$ & $\begin{array}{l}\text { NBS field mill } \\
E(J \neq 0) / E(J=0)\end{array}$ \\
\hline $\begin{array}{l}0.12 \\
0.10\end{array}$ & $\begin{array}{l}1.2 \\
1.0\end{array}$ & $\begin{array}{l}1.16 \\
1.46\end{array}$ & $\begin{array}{l}1.52 \\
1.40\end{array}$ & $\begin{array}{l}1.56 \\
1.55\end{array}$ \\
\hline
\end{tabular}

(b) Covered insulator

$\begin{array}{lllll}0.10 & 1.0 & 1.51 & 1.57 & 1.55 \\ 0.10 & 1.0 & 1.51 & 1.57 & 1.56 \\ 0.10 & 1.0 & 1.51 & 1.57 \mathrm{a} & 1.54\end{array}$

aChopping frequency changed from 100 to $86 \mathrm{~Hz}$.

While the problem of low field readings in the presence of large space charge currents has been eliminated, a unique explanation for the effect has not been found. Some ion current can be expected to flow from the circuit board surface onto the stator and cause a negative contribution to the total signal (see below). However, this mechanism is not expected to produce effects that are as large as $\pm 10 \%$ because of the small area of the circuit board. It may be that some ion current is also continuously deflected onto the stator by the positive charge on the circuit board. However, the magnitude of this focusing effect, also thought to be small, has not been estimated.

Another source of error occurs because of the ion current impinging on the stator and the long time constant (RC) of the stator circuit. While signals due to the chopped conduction current are in quadrature to the induced current signal and largely eliminated by the phase sensitive detector, the long time constant results in the stator acquiring a small positive voltage (the RC time constant is approximately $0.5 \mathrm{~s}$ and the chopping frequency is approximately $90 \mathrm{~Hz}$ ). Thus, a small periodic, local electric field is established between the stator and grounded rotor which is opposite in sign to the external field. Examination of the phase relation of the signal from the local field to that from the external field indicates that the local negative field will contribute to the total signal. 
The maximum amount of this contribution can be estimated by calculating the voltage difference across the input resistor for a given current impinging on the stator. Knowing the voltage of the exposed stator, the approximate magnitude of the local field between the rotor and stator, when the rotor covers the stator, can be calculated. As already indicated, the signal due to the local field is estimated to be less than $0.7 \%$ of that due to the external field. This small systematic error can be reduced by increasing the spacing between the rotor and stator.

During the next quarter, the newly acquired field mill will be retested after two modifications are completed. One will be to increase the rotor-stator spacing from $1 \mathrm{~mm}$ to $3 \mathrm{~mm}$ and the other will be to coat the circuit board with a conducting surface connected to ground.

In addition to the measurements of field meter performance, the evaluation of ion counter measurements is expected to continue. It is anticipated that the off ground measurements using the model transmission line will be completed. The feasibility of using the parallel plate system to study the effects of field penetration and ion current on the operation of the counter in the ground plane in the absence of external air flow will be examined. Similarly, the feasibility of studying the effects of external air flow and ion current in the wind tunnel in the absence of an external field will also be evaluated. We intend for the output of this study to be appropriate guidance in the use of ion counters to determine the ion density in the vicinity of dc transmission lines. To bring together those individuals with a concern for ion measurements or dc field measurements, NBS is hosting a two-day workshop on the measurements of the electrical enviornment near high-voltage de transmission lines on October 27 and 28, 1982. The workshop is intended to provide a forum to discuss the capabilities and limitations of present measurement techniques and to identify future measurement requirements.

In the area of ac measurements, it is expected that two activities will be emphasized. The present schedule calls for the first on-site measurement of $50-\mathrm{Hz}$ electric and magnetic fields to be performed in an exposure system developed for New York State during the coming quarter. In addition, NBS intends to prepare a draft International Electrotechnical Commission standard on the measurement of power frequency electric fields and to distribute this draft to the newly formed working group for comment.

For further information, contact Dr. M. Misakian, (301) 921-3121.

3. TECHNICAL ASSISTANCE FOR FUTURE INSULATION SYSTEMS RESEARCH Subtask No. A053

The objective of this project is to develop diagnostic techniques to monitor, identify, and predict degradation in future compressed gas electrical insulating systems under normal operating conditions. The focus is on the fundamental information and data needed to improve test, design, and performance evaluation criteria. The investigation of partial discharges (corona) in gaseous dielectrics is emphasized. This phenomenon gives rise to degradation of the gas under high electrical stress which leads to breakdown. Measurement of partial discharge inception in highly nonuniform fields may prove to be a preferred method to determine dielectric strength of electronegative gases. 
Planned activities for Fy83 include: 1) completion of an archival paper on basic mechanisms of corona inception in SF 6 under $60 \mathrm{~Hz}$ ac and dc conditions; 2) investigation of the wavelength dependence of photon-induced positivecorona inception in $\mathrm{SF}_{6} ; 3$ ) measurements of power dependence of the rates of oxyfluoride and water vapor production from corona discharges in $S_{6}$, the results of which are to be reported in conference and archival papers; 4 ) exploration of the feasibility of new methods to measure field-enhanced collisional detachment of negative ions in $S_{6}$ and other electronegative gases; 5) improvement in the accuracy of quantitative analysis of trace gases such as $\mathrm{H}_{2} \mathrm{O}$ in $\mathrm{SF}_{6}$ and other gaseous dielectrics using a gas chromatograph/mass spectrometer, and extend the measurements on the effects of trace $\mathrm{H}_{2} \mathrm{O}$ on corona characteristics and relative dielectric strength of the gas; and 6) completion of an archival paper on compilation and evaluation of electron swarm data in molecular electronegative gases.

Activities 1) and 6) were completed in previous quarters. During the past reporting period, measurements were performed which extended activity 2) to include the gas $\mathrm{O}_{2}$. This was necessary in order to verify the conclusions reached from the measurements performed on $S F_{6}$ which were reported in our previous quarterly report [2]. Activity 2) has now been completed. The final results and conclusions obtained from this investigation have been prepared for presentation at the Thirty-Fifth Annual Gaseous Electronics Conference to be held in Dallas, Texas, October 19-22, 1982, and will be highlighted in this report.

Progress was also made on activities 3) and 5). A paper entitled "Effects of $\mathrm{H}_{2} \mathrm{O}$ on the Behavior of $\mathrm{SF}_{6}$ Corona," by R. J. Van Brunt [3] was presented at the Seventh International Conference on Gas Discharges and Their Applications held in London, August 31 - September 3, 1982. The data presented in this paper showed that small quantities of water vapor in SF 6 can significantly influence the electron avalanche growth and level of corona around a positively stressed electrode. In order to better understand these results, it is necessary to measure the $\mathrm{H}_{2} \mathrm{O}$ content in $\mathrm{SF}_{6}$. During the past quarter, a system employing a thin film aluminum oxide hygrometer probe for use in calibrating an existing gas chromatograph-mass spectrometer (GC/MS) for quantitative analysis of $\mathrm{H}_{2} \mathrm{O}$ in $\mathrm{SF}_{6}$ was designed and the necessary components were ordered.

Concerning activity 3), computer programs were written which can be used for rapid analysis of data from the GC/MS system. More measurements were performed [4] to determine the pressure dependence of corona-generated oxyfluoride production rates in $\mathrm{SF}_{6}$. There are no reasons a priori to expect large variations. Although the data accumulated thus far must still be considered preliminary, there appear to be no indications of large variations in the production rates with pressure.

Earlier results show that photodetachment, e.g.,

$$
h_{v}+\mathrm{SF}_{6}{ }^{-} \rightarrow \mathrm{SF}_{6}+\mathrm{e}
$$

makes a negligible contribution to the release of avalanche or coronainitiating electrons in irradiated point-plane gaps containing pure SF 6 to which dc voltages are applied. It was suggested that the enhancement of 
avalanche rates that often results from irradiation of the gap is due to release of photoelectrons from the cathode by scattered radiation, which in the case of stainless steel electrodes in SF 6 requires wavelengths shorter than $350 \mathrm{~nm}$. These photoelectrons quickly attach to $\mathrm{SF}_{6}$ molecules to form stable negative ions which can then give rise to electron release through collisional detachment in the region, near the point electrode, where the ionization coefficient $\alpha$ exceeds the attachment coefficient $\eta_{\text {. Additional }}$ data were obtained for both $\mathrm{SF}_{6}$ and $\mathrm{O}_{2}$ during the past reporting period which lend further support to this interpretation.

Examples of results obtained for $\mathrm{SF}_{6}$ are shown in figure 2. Again stainless steel point-plane electrodes were used with a point-to-plane gap spacing of $1.33 \mathrm{~cm}$ and point radius of curvature of $0.04 \mathrm{~mm}$. The gap configuration is nearly identical to one previously used in the measurement of corona discharge inception [5] and corona pulse characteristics [6] in pressurized $\mathrm{SF}_{6}$. The gas pressure was $300 \mathrm{kPa}$ and the gap was irradiated with uv-radiation directed either at the cathode (plane electrode) or the anode (point electrode) for the wavelengths indicated. The results shown in figure 2 for the case where there was no radiation and when the anode was irradiated for $295 \mathrm{~nm}<\lambda<365 \mathrm{~nm}$ are similar to those previously reported $[5,6]$. For these cases, the discharge below about $21 \mathrm{kV}$ appears in the form of single electron avalanches. At $21 \mathrm{kV}$, there is an abrupt increase in pulse rate, and at this point large "streamer"-type pulses appear and the discharge becomes completely self sustaining, i.e., it is no longer significantly influenced by the radiation.

These results are in sharp contrast to those obtained when the cathode is irradiated. For the latter, there is a more abrupt increase in the avalanche rate near threshold, similar to the behavior observed for negative corona $[5,6]$. By irradiating the cathode, the inception voltage, in fact, comes closer to the theoretically expected value based on the streamer criterion, and the previously reported [5] large difference between positive and negative corona inception is nearly eliminated. As for the results previously reported [2], irradiation of either the anode or cathode required wavelengths shorter than $350 \mathrm{~nm}$ to produce the effects shown. Irradiation of the cathode with $254 \mathrm{~nm}$ radiation from a $\mathrm{Hg}$-discharge lamp was found to produce the most dramatic, observed enhancement in the avalanche rate. There was some evidence that at these higher avalanche rates, formation of the much larger streamer-type pulses is suppressed. The effect here might be similar to that reported for negative corona [6] and should be investigated further.

Since there is a lack of information about the relevant cross sections for photodetachment and collisional detachment processes in $S_{6}$, it is somewhat difficult to argue that photodetachment should be relatively unimportant compared to collisional detachment as observed. However, in the case of $\mathrm{O}_{2}$, the relevant cross sections have been either measured or calculated, and one can show rather convincingly, as previously argued [7], that unless very intense radiation sources are used, the probability of electron release by photodetachment is orders-of-magnitude smaller than that for collisional detachment.

To show this, one must assume some arbitrary flux of negative ions moving toward the point electrode into a region of length $\&$ where $\alpha>n$. This means that within \& the electrical field-to-neutral gas density ratio, $E / N$, exceeds the critical value $(E / N)_{c}$ at which $\alpha=n$; thus if an electron 


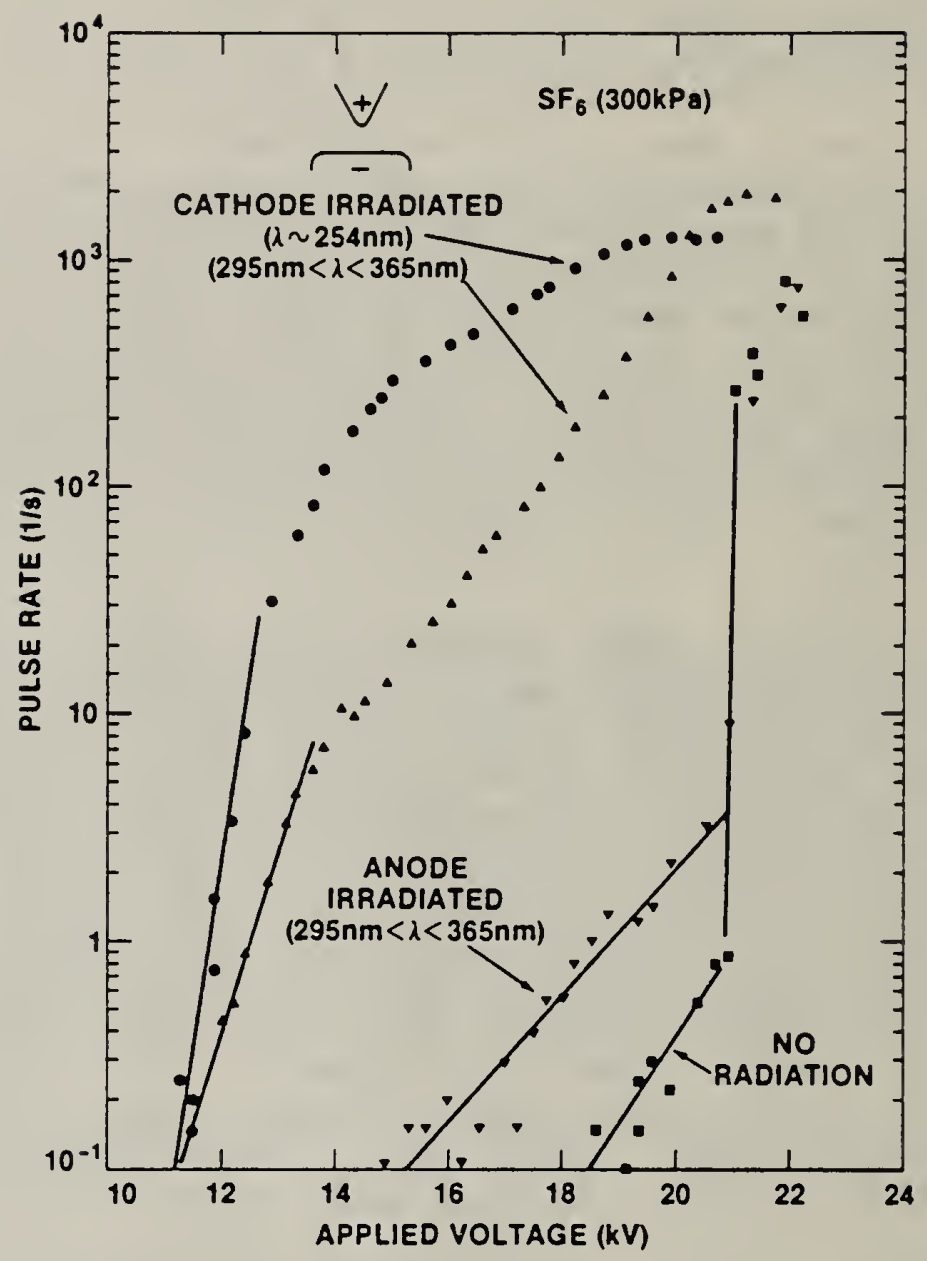

Figure 2. Measured discharge pulse rate versus applied voltage for positive, point-plane corona in $\mathrm{SF}_{6}$ at a pressure of $300 \mathrm{kPa}(\sim 3 \mathrm{~atm})$ for the different indicated conditions of gap irradiation. 
is released, there is a finite probability that it will initiate an avalanche. The probabilities that a negative ion will detach its extra electron, either by encountering a photon of sufficient energy or by colliding at sufficient energy with a neutral molecule, will depend in general on the value of $E / N$ at any given point $x$ in the discharge gap. We consider then the ratio $W_{p, c}$ of the probabilities for photodetachment-to-collisional detachment of an arbitrary ion moving through the distance $\ell$. It can be shown that, to a good approximation, this ratio is given by the expression

$$
W_{p, C}=\frac{\sigma p(\lambda) \Phi(\lambda) \int_{0}^{\ell} d x /(\mu E(x))}{\left\{1-\exp \left[-N \int_{0}^{l}\left(\delta_{d} / N\right) d x\right]\right\}} .
$$

In this equation, $\sigma_{p}(\lambda)$ is the photodetachment cross section at wavelength $\lambda, \Phi(\lambda)$ is the incident photon flux, $\mu$ is the ion mobility, and $\delta d$ is the collisional detachment coefficient, i.e., the number of detachments per unit length. In general, $\delta_{d}$ increases quite rapidly with $E / N$ above a "threshold" value $(E / N)_{d}$ at which a significant number of ions acquire enough kinetic energy from the interaction with the electric field between collisions with neutral molecules to allow detachment to occur, i.e., a kinetic energy which roughly exceeds twice the negative ion electron affinity [5]. The dependence of $\delta_{d}$ on $x$ is derived from the dependence of $E / N$ on $x$.

The detachment coefficient can be derived either from the collision cross sections $\sigma_{c}$ or from the detachment rate coefficients $k$. Using cross section data, the proper expression is:

$$
\delta_{d} / N=\frac{1}{\bar{v}} \quad \int_{0}^{\infty} \quad v \sigma_{c}(v) f(v) d v \text {, }
$$

where $f(v)$ gives the distribution of ion velocities $v$ for which $\bar{v}$ is the mean velocity. For detachment rates, we use the formula

$$
\delta_{d} / N=k / v
$$

In deriving equation (1) above, we have also assumed that

$$
\bar{v}={ }_{\mu} E,
$$

and that

$$
\sigma_{p}(\lambda) \Phi(\lambda) \int_{0}^{\ell} d x /(\mu E(x)) \ll 1,
$$

which is reasonable provided the flux $\Phi(\lambda)$ is not excessively large. 
For the pressures of interest here $(P \geqslant 50 \mathrm{kPa})$, the predominant negative ions in $\mathrm{O}_{2}$ are likely to $\mathrm{O}_{2}^{-}$and $\mathrm{O}_{3}$ [7]. In the following discussion, consideration is given only to $\mathrm{O}_{2}$, although it can be shown that a similar conclusion is reached if one considers $\mathrm{O}_{3}{ }^{-}$. For the present calculation, a gas pressure of $100 \mathrm{kPa}(\sim 1 \mathrm{~atm})$ will be assumed at a uniform temperature of $300 \mathrm{~K}$. Since it is apparent from inspection of equation (1) that $W_{p, c}$ will decrease with increasing $E / N$ (assuming, of course, that $\delta_{d}$ increases with $\left.E / N\right)$, it is sufficient for purposes of this argument to consider an extreme case where $E / N=(E / N)_{c}$ over the entire length $\ell$. In this way, we obtain a kind of upper limit on $W_{p}, c$, since any $E / N$ values higher than $(E / N)_{c}$ will only tend to diminish $W_{p, c}$.

Although to obtain the experimental results on $\mathrm{O}_{2}$, described below, measurements were made using laser and discharge light sources at several wavelengths and intensities, we shall select a case here where the beam was known to be at an optimum intensity corresponding to a flux $\$=8 \times 10 ! 9$ photons $/\left(\mathrm{cm}^{2} \mathrm{~s}\right)$ at $\lambda=595 \mathrm{~nm}$. At this wavelength, the $\mathrm{O}_{2}{ }^{-}$photodetachment cross section is known to be near its maximum value of $\sim 1.5 \times 10^{-18} \mathrm{~cm}^{2}[8]$. The critical $E / N$ for $0_{2}$ is approximately $1.2 \times 10^{-19} \mathrm{~V}^{2}$ [9], and the mobility $\mu$ of $\mathrm{O}_{2}^{-}$is nearly constant over a range of $E / N$ which includes this value $[10]^{2}$. For the present calculation, it was assumed that $\mu=2.0 \mathrm{~cm} 2 /(\mathrm{V} / \mathrm{s})$. Data are also available on the cross sections and rates for collisional detachment of $\mathrm{O}_{2}{ }^{-}$from which values for $\delta_{d}$ can be determined $[7,9,11]$. In this calculation, a constant value of $5 \times 1018 \mathrm{~cm}^{2}$ was assumed for $\delta_{d} / N$. The length $\ell$ of the active region was taken to be $0.05 \mathrm{~cm}$. Although this is much larger than the expected size of the active region in our experiment, it should be noted that the result obtained from equation ( 1 ) is quite insensitive to the assumed value for $\ell$.

Substituting the above values into equation (1) gives the result $W_{p, c}=3.5 \times 10^{-5}$, which means that for radiation intensities achievable, less than one electron avalanche in $10^{4}$ is likely to be initiated by a photodetachment event. Moreover, because of the inhomogeniety of the electric field, E/N will exceed $(E / N)_{c}$ over most of the distance $\ell$, so that $W_{p, c}$ will be even smaller than estimated here. On the basis of this calculation, therefore, one concludes that electron avalanche pulses initiated in $\mathrm{O}_{2}$ via photodetachment cannot be easily observed. Even if sufficient radiation intensity were available, it would be difficult to observe photodetachment in $0_{2}$. This is because at the high laser beam intensities required for photodetachment to compete favorably with collisional detachment, other multiphoton ionization processes are likely to become important during times that the gaps are exposed.

Attempts to observe electron avalanches resulting from photodetachment of negative ions in $0_{2}$ have yielded the expected null results similar to those found for $S_{6}$ [1]. Examples of typical results are shown in figure 3. In this figure, $N_{1}$ and $N_{2}$ are respectively the accumulated avalanche counts in-phase and out-of-phase with the chopped light beam used to induce photodetachment near the tip of the positive point electrode. The error bars represent the calculated statistical uncertainties in the measurement, namely, $\pm 2 \sigma$, where $\sigma=\left(N_{1}+N_{2}\right)^{-1 / 2}$. Since all the data points shown lie within the interval $\pm 2 \sigma$, one must conclude that there were no statistically significant signals that could be attributed to photodetachment. Because the equality of the time intervals for measurement of $N_{1}$ and $N_{2}$ could 


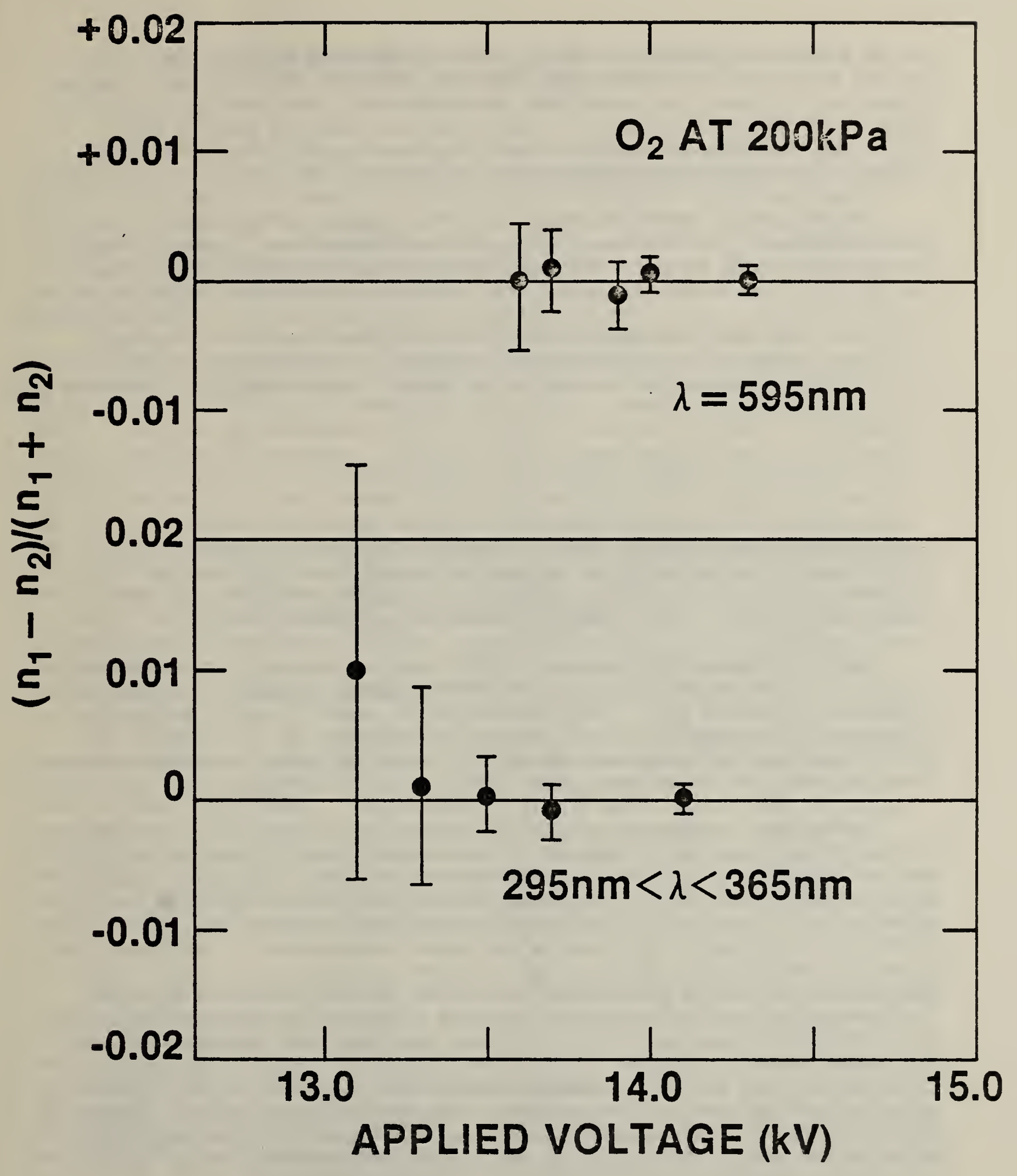

Figure 3. Relative difference in electron avalanche counts for light beam on $\left(\mathrm{N}_{1}\right)$ and light beam off $\left(\mathrm{N}_{2}\right)$ measured for two different indicated conditions of gap irradiation for a positive point electrode in $\mathrm{O}_{2}$ at a pressure of $200 \mathrm{kPa}$ ( $\left.2 \mathrm{~atm}\right)$. The error bars indicate the statistical uncertainties in the measurements. 
not be assured to better than $\pm 0.1 \%$, it would not have been possible to observe fractional differences smaller than this even for arbitrarily large $\mathrm{N}_{1}$ and $\mathrm{N}_{2}$. It should be noted that the data shown correspond to $\mathrm{O}_{2}$ at a pressure of $200 \mathrm{kPa}(\sim 2 \mathrm{~atm})$ in a gap where the electrode spacing was $1.5 \mathrm{~cm}$ and the point electrode radius of curvature was $0.45 \mathrm{~mm}$. Similar results were found at other gas pressures from 50 to $300 \mathrm{kPa}$.

The results of this investigation for $\mathrm{O}_{2}$ support our previous interpretation [1] of the data for $S_{6}$. Since there is no reason to expect the relevant cross sections for $\mathrm{SF}_{6}$ to be drastically different from those for $\mathrm{O}_{2}$, it is reasonable to expect that photodetachment should also play a relatively minor role in the initiation of avalanches for $S_{6}$. Photodetachment could dominate, and possibly be observed under conditions near discharge inception where $(E / N)_{d}>(E / N)_{c}$, i.e., where $\delta_{d} \sim 0$ for electric fields sufficiently high to allow ionization to occur. The limited data available [13] on $\delta_{d} / N$ for the process

$$
S F_{6}^{-}+S F_{6}+S F_{6}+S F_{6}+e,
$$

however, would suggest that $(E / N)_{d}\left\langle(E / N)_{C}\right.$. Thus, unless there is a predominance of other negative ion species having lower $\delta_{d}$, such as clusters $\mathrm{SF}_{\overline{6}}\left(\mathrm{SF}_{6}\right) \mathrm{n}, \mathrm{n}=1,2, \ldots$, there is no basis for expecting that conditions exist for which photodetachment would dominate in $\mathrm{SF}_{6}$.

Again, as emphasized previously [2], these measurements have provided us with a better understanding about the fundamental processes that occur in irradiated discharge gaps. This information is useful from the point-of-view of designing breakdown tests for gaseous insulation. If, for example, one wants to enhance the breakdown probability using radiation, the data presented here indicate that there are preferred methods of irradiation.

During the next quarter our activities will be focused into three main areas. First, an archival paper will be prepared in which the results of our investigation of photon enhanced electron avalanche initiation around a positive point electrode in $\mathrm{SF}_{6}$ and $\mathrm{O}_{2}$ will be described. Secondly, in an effort to bring activity 3) to completion, more measurements will be performed to determine the pressure and power dependencies of the production rates for $\mathrm{SOF}_{2}, \mathrm{SO}_{2}, \mathrm{~F}_{2}, \mathrm{SOF}_{4}$ and $\mathrm{H}_{2} \mathrm{O}$ from corona discharges in $\mathrm{SF}_{6}$. The measurements will also be extended to include negative corona to determine if there are any polarity dependent effects. Finally, a hygrometer probe will be installed and tested in our corona discharge cell for measurement of trace water vapor content in $\mathrm{SF}_{6}$. The probe will initially be used to calibrate the gas chromatograph-mass spectrometer so that the measurements in activity 3) as well as our previous investigations on effects of $\mathrm{H}_{2} \mathrm{O}$ on $\mathrm{SF}_{6}$ corona [2] can be placed on a more quantitative basis. Work may also begin on the design of a system to measure negative ion mobilities and collisional detachment coefficients at high gas pressures.

For further information, contact Dr. R. J. Van Brunt, (301) 921-3121. 


\section{OPTICAL MEASUREMENTS FOR INTERFACIAL CONDUCTION AND BREAKDOWN IN INSULATING SYSTEMS \\ Subtask No. A057}

The objectives of this investigation are to develop apparatus and appropriate procedures for the optical measurements of interfacial electric field and space-charge density in materials for electric power equipment and systems, to understand the interfacial prebreakdown and breakdown processe's in specific insulating systems, and to demonstrate the applicability of the developed instrumentation and the procedures in the development and design of future systems.

Recent effort has been focused on the development of consistent description of the interfacial breakdown process. Previous results from this project [14] have shown that breakdown does not necessarily occur along or at a liquid/solid interface for a paper interface parallel to the field. Initial measurements using pressboard, however, did show a tendency toward interfacial breakdown. Electro-optical measurements were performed to identify any electric field enhancement in the vicinity of the interface [2]. This is an important measurement because measurements in France [15] and in Sweden [16] suggest that space charge effects may dominate the processes at the interface. Electro-optical observations showed that the enhancement of the field in the vicinity of the interface was undetectable, i.e., any enhancement was less than a few percent of the field strength in the fluid at points well removed from the interfacial region. This result led to the current working hypothesis that any interfacial effect in this system is not due to macroscopic field enhancement but is due to the properties of the solid spacer or to the electrode-interface-liquid triple junction.

It is presently assumed, but not yet verified, that the triple junction can be constructed in such a manner that it does not contribute to any lowering of the breakdown strength. This was accomplished in the previous work on paper interfaces. The properties of the solid spacer that have been identified as possibly being significant include serving as a source for bubbles or as an area in which the particle density is larger. The particle density can be higher either because microscopic particles are trapped on the spacer and are removed when the field is applied or because the electrohydrodynamic flow can cause particles to be deposited in the vicinity of the interface [15].

NBS investigations into the processes of breakdown in insulating liquids suggest that bubbles and particles may have similar effects on the breakdown process. To isolate the effects of particles, aluminum, carbon, alumina, and cellulose particles were introduced into such liquids as transformer oil, hydrocarbon fluids, and water, and the breakdown process was photographed. The general result from these studies is that a relatively large density of particles stimulates the transition from the slower modes of streamer propagation to the faster modes [17]. This has the effect of shortening the time to breakdown. The process is reversible in that filtering the fluid retards the transition of slow modes of streamer propagation to faster modes. 
Based on these results, it seems probable that bubbles at the pressboard liquid interface act as conducting particles at high field strength and because they are not readily mobile at the interface, they would enhance the breakdown probability along the interface. This hypothes is will be evaluated by replacing the pressboard interface. Careful attention will be paid to handling the interfacial material and a new liquid-handling system will be developed to allow degassing of the oil (as well as water removal) during the course of the experiment in order to dissolve any gaseous breakdown by-products.

In order to investigate the properties of paper interfaces at high temperatures, a new cell will be designated permitting a changing of the interface without opening the cell. All the above experiments will provide us with information so that the field modifications due to an interface alone may be measured electro-optically.

For further information, contact Dr. E. F. Kelley, (301) 921-3121.

\section{ACTIVE INSULATORS FOR INSULATION AND SURGE SUPPRESSION Subtask No. A057}

The objective of this investigation is to evaluate the practicality of using active insulators, i.e., insulators made from materials whose resistance is a function of the voltage across the device, to minimize the effects of switching and lightning surges. The theoretical aspect consists of the development of a mathematical model for a single phase electric power system which can be used to predict the effects of active insulators. The experimental activity is the development of a materials research facility to fabricate insulation materials suitable for use in an active insulator. This work is being performed by the Department of Electrical Engineering, University of Southern California, under a grant from the National Bureau of Standards.

The single-phase transmission line mathematical model with active insulator string was developed based on Bergeron's method. The equivalent circuit for such a transmission line is shown in figure 4 for line segments and figure 5 for a voltage source with breaker resistance $R_{b}$ and source inductance $L$. The modified surge impedance $Z^{\prime}$ is equal to $Z$ (line surge impedance) plus $R$ ( 1 ine segment resistance), and the line loss factor is:

$$
S=\frac{Z-R / 2}{Z+R / 2} \text {. }
$$

A series of voltage and current equations were derived with only one unknown variable and the rest of the equation consisted of either line constants and/or known variables. The nodal voltage equation was nonlinear and was solved using Newton-Ralphson's iteration method. Since the nonlinear equation would have more than one solution, the initial value for the iteration was critical in order to obtain a reasonable solution. Thus far, the best initial value was the nodal voltage at $t-\Delta t$, where $\Delta t$ was the incremental time step. 


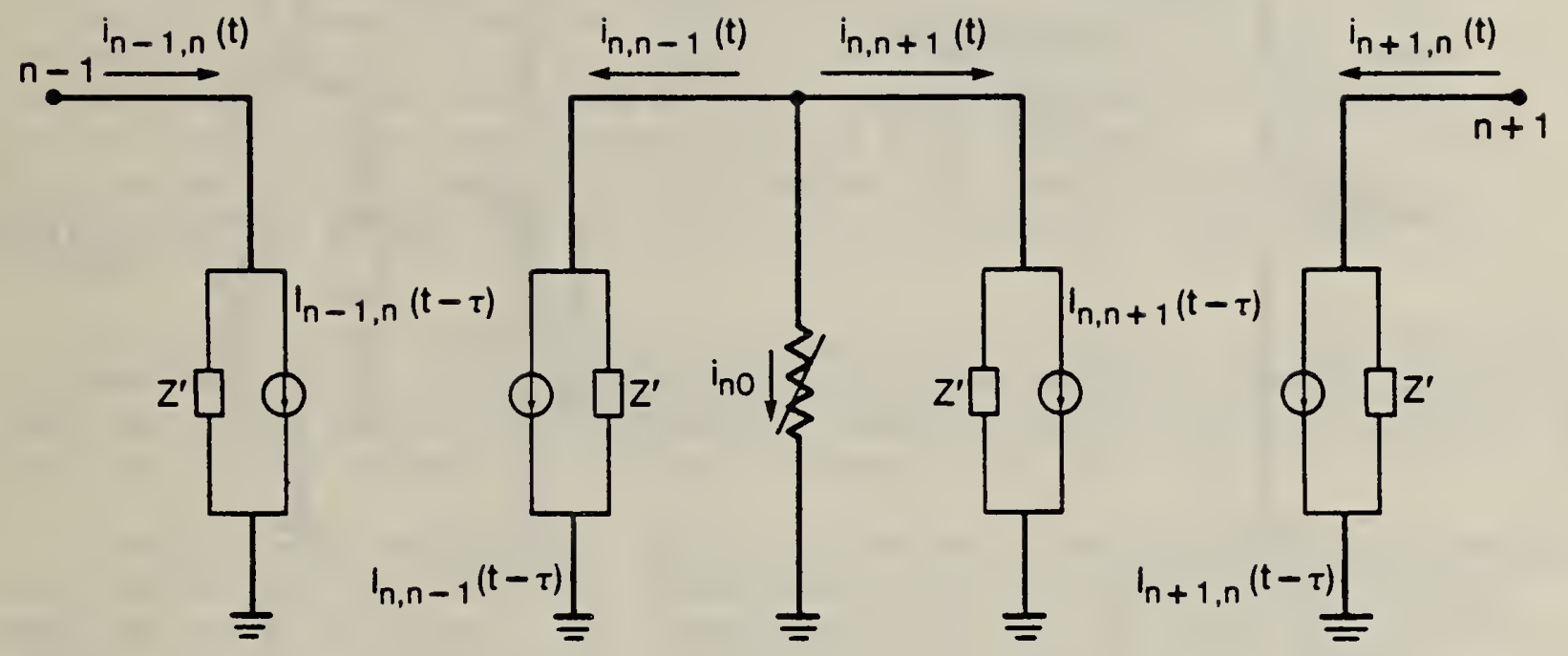

Figure 4. Equivalent circuit for single phase transmission line with an active insulator. 


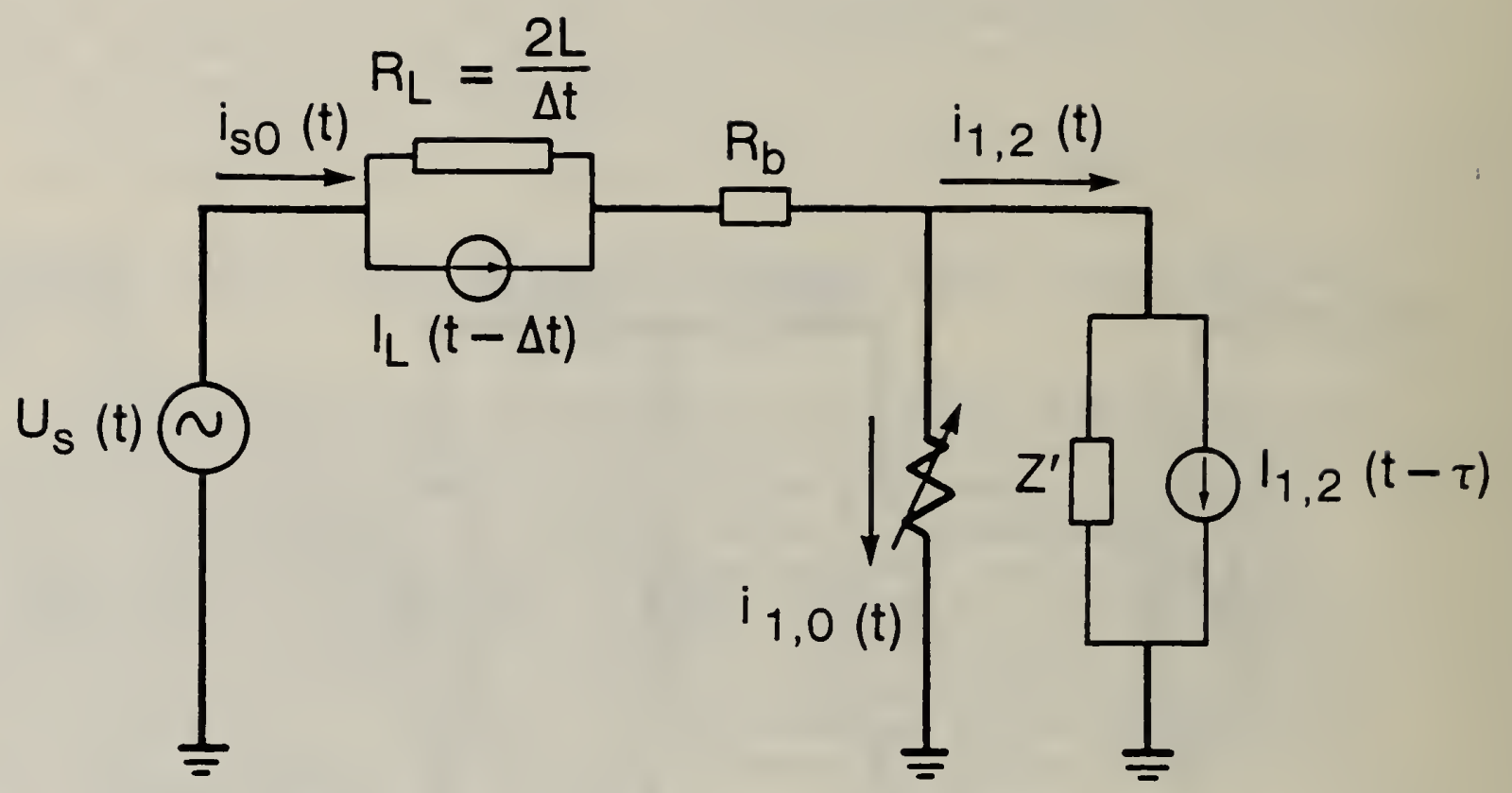

Figure 5. Equivalent circuit for a voltage source with breaker resistance $R_{b}$ and a source inductance $L$. 
The analysis was carried out using computer programs based on this model. The transmission line was divided equally into nine sections. The sending end and receiving end arresters were assumed to have the same current-voltage characteristics as the active insulator strings. For comparison purposes, the station arresters were also included under all conditions. The overvoltages under switching conditions were studied under two different switching sequences, namely, (1) switch closed at maximum voltage level and (2) switch closed at maximum voltage level with subsequent switch open at current zero level and closed át next current zero level. Results showed that under the first switching sequence the maximum overvoltages on the transmission line were 1.4 p.u. (p.u. = per unit, i.e., 1.4 p.u. is 1.4 times the normal operating voltage) with eight active insulator strings evenly positioned between the two terminals. The maximum overvoltage was $1.75 \mathrm{p} . u$. without any active insulators. The overvoltage was about the same throughout the line when active insulators were employed. Without them, however, line segments between the terminals sustained considerably higher overvoltage. The peak current passing through arresters was 350 amperes without active insulators as compared to about 40 amperes with active insulators. Under the closeopen-reclose sequence, results showed that the maximum overvoltages were $1.45 \mathrm{p} . \mathrm{u}$. with active insulators and $2.25 \mathrm{p} . \mathrm{u}$. without active insulators. Both of these maximum overvoltages occurred after reclosure. These results indicate that active insulators could reduce the transient overvoltage considerably and the thermal ratings of station arresters could be greatly reduced.

The material research facility has been set up with most of the necessary equipment installed. Plate-type samples were fabricated for electrical testing. Electrical tests showed that the material produced had a dielectric constant of less than 4.0 and volume resistivity of greater than $1013 \Omega-\mathrm{cm}$.

Plans for the next quarter include extension of the single-phase transient model to include lightning transients, for lightning strikes either on the conductor or on the tower. The three-phase model will be developed next for switching transient conditions. In addition, the materials fabrication facility will be completed and the procedure and formulations will be improved to reach comparable values as other insulating materials become available.

For further information, contact Dr. T. C. Cheng, (213) 743-6938. 


\section{REFERENCES}

[1] M. Misakian, Generation and Measurement of DC Electric Fields with Space Charge, J. App 1. Phys., Vol. 52, pp. 3135-3144, 1981.

[2] Development of Power System Measurements --- Quarterly Report, Apri1 1, 1982 to June 30, 1982, R. E. Hebner, Editor, Nat. Bur. Stand. (U.S.), NBSIR 82-2586 (Oct. 1982).

[3] R. J. Van Brunt, Effects of $\mathrm{H}_{2} \mathrm{O}$ on the Behavior of $\mathrm{SF}_{6}$ Corona, Proc. 7 th Int. Conf. on Gas Discharges and Their Applications, Peter Peregrinus Ltd., pp. 255-258, 1982.

[4] R. J. Van Brunt and D. A. Leep, Corona-Induced Decomposition of SF6, Gaseous Dielectrics III, Proc. of the 3rd Int. Symp. on Gaseous Dielectrics, ed. by L. G. Christophorou, Pergamon Press, pp. 402-409, 1982.

[5] R. J. Van Brunt and M. Misakian, Mechanisms for Inception of DC and 60- Hz AC Corona in SF, IEEE Trans. Elec. Insul., Vol. EI-17, No. 2, pp. 106-120, Apr. 1982 .

[6] R. J. Van Brunt and D. Leep, Characterization of Point Plane Corona Pulses in SF 6 , J. Appl. Phys. Vol. 52, No. 11, pp. 6588-6600, Nov. 1981.

[7] W. F. Schmidt and R. J. Van Brunt, Comments on the Effect of Electron Detachment in Initiating Breakdown in Gaseous Dielectrics, Gaseous Dielectrics III, Proc. of the 3rd Int. Symp. on Gaseous Dielectrics, ed. by L. G. Christophorou, Pergamon Press, pp. 561-563, 1982.

[8] D. W. Goodson, R. J. Corbin, and L. Frommhold, Electron Avalanches in Dxygen: Detachment from Diatomic ion $0_{2}$, Phys. Rev. A, Vol. 9, No. 5, pp. 1049-2059, May 1974 .

[9] P. C. Cosby, R. A. Bennett, J. R. Peterson, and J. T. Moseley, Photodissociation and Photodetachment of Molecular Negative Ions. II. Ions Formed in Oxygen, J. Chem. Phys., Vol. 63, No. 4, pp. 1612-1620, August 1975.

[10] J. W. Gallagher, E. C. Beaty, J. Dutton, and L. C. Pitchford, A Survey of Electron Swarm Data in Electronegative Gases, J. Chem. and Phys. Ref. Data (in press).

[11] L. G. McKnight, Drift Velocities and Interactions of Negative Ions in Oxygen, Phys. Rev. A, Vol. 2, No. 3, pp. 762-770, Sept. 1970.

[12] J. A. Rees, Fundamental Processes in the Electrical Breakdown of Gases, Electrical Breakdown of Gases, ed. by J. M. Meek and J. D. Craggs, John Wiley and Sons, pp. 1-128, 1978.

[13] B. C. O'Neill and J. D. Craggs, Collisional Detachment of Electrons in Sulphur Hexafluoride, J. Phys. B: Atom. Molec. Phys., Vol. 6, pp. 2634-2640, Dec. 1973. 
[14] E. F. Kelley and R. E. Hebner, Electrical Breakdown in Composite Insulating Systems: Liquid-Solid Interface Parallel to the Field, IEEE Trans. Elec. Insul., Vol. EI-16, pp. 297-303, 1981.

[15] J. D. Cross, Breakdown at Liquid/Solid Interfaces and the Role of EHD in Liquid Breakdown, 1982 Conference on Electrical Insulation and Dielectric Phenomena (in press).

[16] U. Gafvert, $0 i 1$ and Particle Motion Close to Electrode Surfaces, 1982 Conference on Electrical Insulation and Dielectric Phenomena (in press).

[17] E. F. Kelley and R. E. Hebner, Prebreakdown Phenomena Between Sphere-Sphere Electrodes in Transformer 0il, Appl. Phys. Lett., Vol. 38, pp. 231-233, 1981. 

NBS-114A (REV. $2 \cdot 8 C)$

\begin{tabular}{|c|c|c|c|}
\hline $\begin{array}{l}\text { U.S. DEPT. OF COMM. } \\
\text { BIBLIOGRAPHIC DATA } \\
\text { SHEET (See instructions) }\end{array}$ & $\begin{array}{l}\text { 1. PUBLICATION OR } \\
\text { RERORT NO } \\
\text { NBSIR } 83-2705\end{array}$ & 2. Performing Organ. Report No. & $\begin{array}{r}\text { 3. Publication Date } \\
\text { May } 1983\end{array}$ \\
\hline \multicolumn{4}{|c|}{$\begin{array}{l}\text { 4. TITLE AND SUBTITLE } \\
\text { Development of Power System Measurements -- Quarterly Report } \\
\text { July } 1,1982 \text { to September 30, } 1982\end{array}$} \\
\hline \multicolumn{4}{|c|}{$\begin{array}{l}\text { 5. AUTHOR(S) } \\
\text { R. E. Hebner, Editor }\end{array}$} \\
\hline \multicolumn{3}{|c|}{$\begin{array}{l}\text { 6. PERFORMING ORGANIZATION (If joint or other thon NBS, see in structions) } \\
\text { NATIONAL BUREAU OF STANDARDS } \\
\text { DEPARTMENT OF COMMERCE } \\
\text { WASHINGTON, D.C. } 20234\end{array}$} & $\begin{array}{l}\text { 7. Contract Grant No. } \\
\text { T.0. No. } 137 \\
\text { 8. Type of Report \& Period Covered } \\
\text { Quarterly } \\
7 / 1 / 82-9 / 30 / 82\end{array}$ \\
\hline \multicolumn{4}{|c|}{$\begin{array}{l}\text { 9. SPONSORING ORGANIZATION NAME AND COMPLETE ADORESS (Street. City. State, ZIP) } \\
\text { Department of Energy } \\
\text { Division of Electric Energy Systems } \\
\text { 1000 Independence Ave., S.W. } \\
\text { Washington, DC } 20585\end{array}$} \\
\hline
\end{tabular}

10. SUPPLEMENTARY NOTES

Document describes a computer program; SF-185, FIPS Software Summary, is attached.

11. ABSTRACT (A 200-word or less foctual summary of most significant information. If document includes a significant bibliography or literature survey, mention it here)

This report documents the progress on four technical investigations sponsored by the Department of Energy. Three were performed by the Electrosystems Division, the National Bureau of Standards and the fourth by the Department of Electrical Engineering of the University of Southern California. The work described covers the period from July 1, 1982 to September 30, 1982. The report emphasizes the calibration of instruments designed to measure the 60-Hz electric field in biological exposure facilities, the determination of the role of photodetachment of $S F_{6}$ corona discharges, the measurement of failure mechanisms in liquid/solid insulating systems, and the development and behavior of active insulators.

12. KEY WORDS (Six to twelve entries; alphabetical order; capitalize only proper names; and separate key words by semicolons) cables; composite insulation; dc fields; high voltage; incipient fault; insulation; liquid breakdown; SF6; space charge; transformer $0 i 1$.

13. AVAILABILITY

XX Unlimited

14. NO. OF PRINTED PAGES

For Official Distribution. Do Not Release to NTIS

Order From Superintendent of Documents, U.S. Government Printing Office, Washington, D.C. 20402.

15. Price

[ Order From National Technical Information Service (NTIS), Springfield, VA, 2216 


